\begin{tabular}{|l|l|l||}
\hline \multicolumn{2}{|c|}{ PublisherInfo } \\
\hline \hline PublisherName & $:$ & BioMed Central \\
\hline \hline PublisherLocation & $:$ & London \\
\hline \hline PublisherImprintName & $:$ & BioMed Central \\
\hline \hline
\end{tabular}

\title{
Evidence for organelle origin
}

\begin{tabular}{|l|l|l||}
\hline \multicolumn{2}{|c|}{ ArticleInfo } \\
\hline \hline ArticleID & $:$ & 5064 \\
\hline \hline ArticleDOI & $:$ & $10.1186 /$ gb-spotlight-20050303-01 \\
\hline \hline ArticleCitationID & $:$ & spotlight-20050303-01 \\
\hline \hline ArticleSequenceNumber & $:$ & 40 \\
\hline \hline ArticleCategory & $:$ & Research news \\
\hline ArticleFirstPage & $:$ & 1 \\
\hline \hline ArticleLastPage & $:$ & 3 \\
\hline \hline & & RegistrationDate : 2005-3-3 \\
\hline ArticleHistory & $:$ & OnlineDate \\
\hline \hline ArticleCopyright & $:$ & BioMed Central Ltd2005-3-3 \\
\hline \hline ArticleGrants & $:$ & \\
\hline \hline ArticleContext & $:$ & 130596611 \\
\hline \hline
\end{tabular}




\section{Charles Q Choi}

Email: cqchoi@nasw.org

The first genetic evidence of hydrogenosomes - organelles found in some ciliates, trichomonads, and fungi that generate hydrogen and adenosine triphosphate (ATP) - that evolved from mitochondria is reported by Dutch and German researchers in Nature this week.

"Our findings prove the existence of missing links between mitochondria and hydrogenosomes," coauthor Johannes Hackstein of Radboud University Nijmegen in the Netherlands told The Scientist. "This has value in analyzing the evolution of the eukaryotic cell, to help better understand these organelles and possibly mitochondrial dysfunctions."

Hydrogenosomes resemble mitochondria morphologically, but generally lack a genome, hampering clarification of their origin. Considerable debate exists over whether hydrogenosomes evolved from aerobically functioning mitochondria that acquired an anaerobic metabolism or from endosymbionts capable of both aerobic and anaerobic function that mitochondria also descended from.

In 1998, Hackstein and colleagues found preliminary evidence that hydrogenosomes of the anaerobic ciliate Nyctotherus ovalis from cockroach guts might possess genes. In the research team's latest study, long-range polymerase chain reaction (PCR) on N. ovalis hydrogenosome DNA yielded a 12-kilobase fragment of the organellar genome that encodes four genes of a mitochondrial complex I ( nad2, nad $4 \mathrm{~L}$, nad5, and $n a d 7$ ), two genes encoding mitochondrial ribosomal proteins (RPL2 and RPL14), and a tRNA tyrosine gene. The genes exhibit distinct mitochondrial codon usage, and complementary DNAs isolated for $n a d 5$ and nad7 show they are transcribed.

Investigating $N$. ovalis, the researchers identified three more mitochondrial I complex genes in its nucleus, for a total of seven of the 14 core genes needed for that complex. Hackstein and colleagues also found genes for half of the proteins of mitochondrial complex II, the Fp and Ip subunits, in the nucleus. Phylogenetic analysis with a discrete gamma-distribution model revealed that both hydrogenosomal and nuclear genes appear well conserved and that they cluster with their homologues from the mitochondrial genomes of aerobic ciliates.

The $N$. ovalis hydrogenase's catalytic center clusters neither with hydrogenases from eukaryotes nor with any of the hydrogenase-related Nar proteins that seem shared by all eukaryotes. Rather, the $N$. ovalis hydrogenase is more closely related to delta proteobacterial [Fe] hydrogenases. "This implies that the hydrogenase was acquired by lateral gene transfer," Hackstein said, adding weight to the idea the organelle was a mitochondrion that became a hydrogenosome secondarily.

"This encourages speculation and investigation of what other organelles might have had a similar origin of losing their genomes," said Frederic Bushman of the University of Pennsylvania in Philadelphia, who did not participate in this study. "Maybe peroxisomes did, and Lynn Margulis has suggested the microtubule network has descended from spirochetes."

"This does not mean that all hydrogenosomes evolved from mitochondria," Hackstein emphasized. Patricia Johnsonof the University of California at Los Angeles, who did not participate in this study, noted the distribution of hydrogenosomes throughout the eukaryotic family tree "strongly suggests they arose multiple times independent of each other." 
Moreover, $N$. ovalis is quite different from other hydrogenosome-bearing organisms in that it belongs to a clade in which mitochondria are common and apparently uses pyruvate dehydrogenase instead of pyruvate ferredoxin oxidoreductase for oxidative decarboxylation. "It isn't clear whether these findings are relevant to hydrogenosomes in other lineages," Johnson said.

In the future, Hackstein plans to use Southern blotting to analyze the complete hydrogenosomal genome, estimated at 60 kilobases. "It would be very interesting to see how this organelle produces ATP and what happens with electron flow given the apparent presence of complex I and II and the absence of III and IV," Johnson told The Scientist.

Since the hydrogenosomes appeared insensitive to inhibitors of mitochondrial complexes III and IV, future studies could reveal whether the genes for those complexes are missing or inactivated. "Not much is known about the inactivation of genes in organelles. This could be a great opportunity," Hackstein said.

"For the pathogenic bugs that contain hydrogenosomes, you can think about drug targets unique to these organelles seen in these creatures but not humans," Bushman told The Scientist.

\section{References}

1. B. Boxma et al. "An anaerobic mitochondrion that produces hydrogen." Nature 434: 74-9, March 3, 2005., [http://www.nature.com]

2. A. Akhmanova et al., "A hydrogenosome with a genome," Nature, 396:527-8, December 10, 1998.

3. F.D. Bushman. "Evolutionary teamwork," The Scientist: May 10, 2004., [http://www.thescientist.com/2004/5/10/33/1]

4. Patricia J. Johnson, [http://www.uclaaccess.ucla.edu/cfm/access_faculty.cfm?FacultyKey=58] 